\title{
O PAPEL DA TRADUÇÃO NA CONSTITUIÇÃO DA PROSA FUNDAMENTAL BÚLGARA ${ }^{1}$
}

\author{
LE RÔLE DE LA TRADUCTION DANS LA CONSTITUTION DE LA \\ PROSE FONDAMENTALE BULGARE
}

\section{THE ROLE OF TRANSLATION IN THE CONSTITUTION OF BULGARIAN FUNDAMENTAL PROSE}

\author{
Irena KRISTEVA ${ }^{2}$ \\ Tradução de: Clarissa Prado MARINI ${ }^{3}$
}

\begin{abstract}
Resumo: Esse estudo propõe examinar a evolução da tradução na Bulgária com o objetivo de demonstrar que a literatura búlgara, como toda "jovem" literatura, nasceu da tradução. Baseando-se no conceito bermaniano da prosa fundamental, esse trabalho buscará ilustrar, através de exemplos, o papel decisivo que a tradução desempenhou ao longo das diferentes épocas dessa literatura. A apresentação das principais questões tradutórias revelará as duas características essenciais dessa atividade ao mesmo tempo fundadora e compensadora para provar que ela contribuiu para a constituição da identidade nacional, para a ampliação da cultura búlgara e para a consolidação de seu polissistema literário. A reflexão será articulada em três tempos. Primeiramente, ela analisará a relação entre tradição e tradução. Em seguida, ela retraçará o trajeto da Bulgária a partir do primeiro ensaio de tradução das Santas Escrituras por Cirilo e Metódio, o qual serviu de modelo às experiências de escrita posteriores, contribuindo para a formação da identidade linguística. Enfim, o estudo buscará ressaltar alguns fatos de destaque da história da tradução na Bulgária, que influenciaram a criação literária.
\end{abstract}

Palavras-chave: Cultura. Polissistema literário. Prosa fundamental. Tradução. Tradição.

Résumé : Cette étude se propose d'examiner l'évolution de la traduction en Bulgarie dans l'objectif de démontrer que la littérature bulgare, comme toute « jeune » littérature, est née de la traduction. En s'appuyant sur le concept bermanien de prose fondamentale, elle cherchera à illustrer, à travers des exemples, le rôle décisif que la traduction a joué au cours des différents âges de cette littérature. L'esquisse des enjeux majeurs traductionnels tâchera de révéler les deux caractéristiques essentielles de cette activité à la fois fondatrice et compensatrice pour prouver qu'elle a contribué à la constitution de l'identité nationale, à l'épanouissement de la culture bulgare et à la consolidation de son polysystème littéraire. La réflexion s'articulera en trois temps. D'abord, elle interrogera le rapport entre la tradition et la traduction. Ensuite, elle retracera le cheminement propre à la Bulgarie à partir du premier essai de traduction des Saintes Ecritures par Cyrille et Méthode, lequel, en contribuant à la formation de l'identité linguistique, a servi de modèle aux expériences d'écriture ultérieures. Enfin, elle cherchera à mettre en valeur quelques faits saillants de l'histoire de la traduction en Bulgarie, qui ont influencé la création littéraire.

\footnotetext{
${ }^{1}$ Nota da Tradutora (NT): artigo publicado originalmente em francês na revista acadêmica italiana Ticontre. Teoria Testo Traduzione, em 2015. Tradução autorizada pela autora (e-mail datado de 15 de maio de 2018), e pelo comitê editorial da revista, na pessoa de Matteo Fadini (e-mail datado de 16 de maio de 2018). Referência bibliográfica completa do artigo original: KRISTEVA, Irena. Le rôle de la traduction dans la constitution de la prose fondamentale bulgare. Ticontre. Teoria Testo Traduzione, iii (2015), p. 125-140. ISSN: 2284-4473. Disponível em: <http://www.ticontre.org/ojs/index.php/t3/article/view/52>. Acesso em: maio de 2018.

${ }^{2}$ Professora associada da Faculdade de Letras Clássicas e Modernas da Universidade de Sofia "São Clemente de Ocrida" (Sofia University "St. Kliment Ohridski"/Софийски университет "Св. Климент Охридски"). Doutora em Semiologia do Texto e da Imagem pela Universidade Paris 7. E-mail: irena_kristeva@yahoo.com

${ }_{3}$ Doutoranda no Programa de Pós-Graduação em Estudos da Tradução-PGET, com bolsa CAPES. Período sanduíche na Université Paris-Sorbonne, Paris IV com bolsa CAPES. E-mail: clarissamarini@gmail.com
} 
Mots-clés : Culture. Polysystème littéraire. Prose fondamentale. Traduction. Tradition.

\begin{abstract}
This study aims to examine the evolution of translation in Bulgaria in order to demonstrate that Bulgarian literature, as every " young » literature, was born in the translational act. Based on the Berman's concept of fundamental prose, it will seek to illustrate, through examples, the decisive role that translation played in the stages of this literature. The outline of the major translational issues will try to reveal the two essential characteristics of this founder and compensatory activity, and prove that the translation has contributed to the constitution of national identity, the development of Bulgarian culture and the consolidation of his literary polysystem. The reflection will be structured in three parts. Firstly, it will examine the relationship between tradition and translation. Secondly, it will draw the Bulgarian translational motion that began with the translation of the Holy Scriptures by Cyril and Methodius, which served as a model for subsequent writing experiences and contributed to the formation of national identity and language. Finally, it will seek to emphasize some of the highlights of the Bulgarian history of translation and their influences on literary creation.
\end{abstract}

Keywords: Culture. Literary polysystem. Fundamental prose. Translation. Tradition.

A visão de mundo é definida em grande medida pelas relações entre a língua, a cultura e o modo de vida. Mas o que acontece quando as visões de mundo da língua-fonte e da línguaalvo são incomparáveis, incomensuráveis ou incompartilháveis? Quando as duas línguas apresentam diferenças tão importantes que se torna impossível realizar a intenção da qual Benjamin ${ }^{4}$ fala? Tomemos o caso das línguas menores faladas em pequenas comunidades: tratase tanto de pequenos países como a Bulgária ou os Países Baixos, que têm uma tradição de tradução secular, quanto das populações colonizadas do Terceiro Mundo, cuja tradição é sobretudo oral. Consideradas como línguas “fracas” em relação às grandes línguas europeias, a submissão, e até mesmo a mutação imposta às línguas menores pela tradução parece mais provável do que o inverso. No seio das línguas "fortes" e "fracas" se manifestam então tendências e influências assimétricas, próprias à cultura em geral.

$\mathrm{Na}$ origem das "jovens" literaturas se encontra o ato de traduzir. A literatura búlgara, que não é uma exceção, baseia-se em fundamentos teológicos estabelecidos e fortificados pela tradução. Por seu gesto pioneiro da tradução dos Livros litúrgicos, os irmãos Cirilo e Metódio conferem à língua eslava o estatuto de língua literária. Ao enriquecer essa língua pelos calques e empréstimos, e ao aperfeiçoar sua qualidade estilística, seus discípulos preparam o terreno para a literatura búlgara. Ora, os grandes centros da escrita eslava na Idade Média não faziam a distinção entre a escritura e literatura, e ainda menos entre texto-fonte e texto-alvo. A prosa

\footnotetext{
${ }^{4}$ A saber, a compreensão compartilhada, a vida comum dos mundos do original e da tradução que o tradutor tenta ampliar e unir. Ver Walter Benjamin, La tâche du traducteur, in : Idem, Euvres, traduzido por Maurice de Gandillac, Paris, Gallimard, 2000, i, p. 244-262. [NT: Em português, BENJAMIN, Walter. A tarefa do tradutor. Tradução de Susana Kampff Lages. In: Escritos sobre Mito e Linguagem, Rio de Janeiro: Editora 34, 2011, p. 101119.]
} 
fundamental búlgara não se caracteriza então por sua originalidade de ideias e de formas, mas sim por um mimetismo inspirado pelos textos sagrados do cristianismo.

As "jovens" literaturas têm tendência a incorporar certas obras traduzidas em seu polissistema literário para preencher as lacunas. A relação muitas vezes conflituosa entre as traduções e os outros elementos do polissistema literário búlgaro determina seu dinamismo. E já que todo texto está inscrito numa intertextualidade, a "interação textual" supõe a mudança dos elementos culturais e linguísticos das obras anteriores pelas obras traduzidas. Assim, a tradução “transforma as 'estruturas profundas' da herança - verbal, temática, iconográfica - em ‘estruturas de superfície' do quotidiano e da referência social”' (STEINER, 1978, p. 395)

\section{Tradução e tradição}

Se a modernidade impõe o racionalismo como "mestre e possessor" (DESCARTES, 1966, p. 84) ${ }^{6}$ do mundo, a visão tradicional encerra as ações e os saberes humanos na finitude. Transmitida pela memória reflexiva, a tradição preserva uma transcendência da existência humana (a "pura ideia" dos românticos) e não sua manifestação específica (sua expressão grega, latina ou búlgara). Enquanto agente da modernidade e pela novidade que ela traz consigo, a tradução corre o risco de interromper "a transmissibilidade das formas de experiência, a relação com a origem fundadora e o equilíbrio da naturalidade e da artificialidade" (BERMAN, 1988, p. 89) que caracterizam a tradição. Em resumo, a tradução ameaça perturbar a tradição. É porque, na sua tradição plurissecular, a tradução foi dominada pela vontade de domesticar o estrangeiro e marcada pela repulsa ao diferente. Hoje, finalmente compreendemos que ela deve levar em consideração a cultura estrangeira e respeitar o Outro portador dessa cultura. Especialmente porque o medo do estrangeiro sempre coabitou com o gosto pelo estrangeiro. Essa visada ética da tradução é bem resumida por "a prova do estrangeiro" (BERMAN, 1984) 7 que percebe a prova na sua dupla acepção de pena afligida e de operação de avaliação. A tradução e transforma assim em metáfora e paradigma da coexistência e da interação das culturas e dos homens que falam línguas diferentes, mas pertencem à mesma humanidade.

A conotação primária comum dos termos tradição, translação e tradução determina seu uso atual. A tradição designa a relação de uma cultura com sua própria origem, transmite as

\footnotetext{
${ }^{5}$ [NT: Em português, STEINER, George. Depois de Babel: questões de linguagem e tradução. Tradução de Carlos Alberto Faraco. Curitiba: Editora da UFPR, 2005.]

${ }^{6}$ [NT: Em português, Discurso do método (várias edições)]

${ }^{7}$ [NT: Em português, BERMAN, Antoine. A prova do estrangeiro: Cultura e tradução na Alemanha romântica. Tradução de Maria Emília Pereira Chanut. Bauru, SP: EDUSC, 2002.]
} 
ações e os costumes dos ancestrais, preserva os modelos fundadores, protege o patrimônio. A translação "recobre a quase-totalidade dos domínios possíveis de transferência e de transmissão no interior de um mundo determinado pela transmissividade": transferência dos textos, das obras de arte, do saber. A tradução, que realiza a "transferência do sentido" de uma cultura a outra, torna-se uma das formas dessa transmissão e ao mesmo tempo uma forma de apropriação da herança cultural (BERMAN, 1988, p. 85-89).

Ambas, a tradução e a tradição, contaram na evolução do mundo europeu e na formação de sua cultura. A própria noção de Europa une a Antiguidade e os Tempos Modernos, o Oriente e o Ocidente. Separados por seu espírito e sua evolução, esses mundos estão:

\begin{abstract}
tão imbricados um no outro, tão unidos pela lembrança consciente e a continuidade de sua história, que nosso mundo moderno, apesar de sua novidade e seu caráter próprio, está em todos os pontos impregnado e condicionado pela civilização antiga, sua tradição, sua concepção do direito e do Estado, sua língua, sua filosofia e sua arte. É isso e somente isso que dá ao mundo europeu sua profundidade, sua amplitude, sua complexidade, sua circulação, assim como seu gosto pelo pensamento e pela autoanálise históricos. ${ }^{8}$
\end{abstract}

$\mathrm{Na}$ aurora da história europeia da tradução, a tradução da Bíblia é uma tentativa de construir uma passarela entre esses dois mundos, de promover as trocas espirituais entre o Oriente e o Ocidente, de restabelecer a comunicação interrompida pela catástrofe de Babel. Além da difusão da Boa Nova, as traduções das Santas Escrituras em velho eslavo por Cirilo e Metódio no século IX, na língua nacional alemã por Lutero (1545), em inglês pela King James Version (1611), têm o mérito de ter anulado a prerrogativa de "línguas sagradas" do hebreu, do grego e do latim, "santificando" línguas vernáculas. Com o nascimento da língua nacional, a tradução se inscreve num vasto projeto ideológico e religioso que dá continuidade à afirmação e emancipação da nação. Ela se revela um elemento fundamental para o desenvolvimento da cultura. Ela contribui para a constituição da identidade nacional e linguística na Europa, até mesmo para a formação da identidade europeia através do acesso ao Verbo pelos povos europeus.

A Idade Média é sem dúvida o tempo da instauração da prosa fundamental búlgara. Os "escritos num meio idêntico" para uma cultura compõem a prosa fundamental. Essa "base mínima de todo texto prosaico [...] contém todos os elementos necessários à escrita em prosa" (BERMAN, 2012, p. 43). Sua constituição implica de início a criação de:

\footnotetext{
${ }^{8}$ Erns Troeltsch, Der Historismus und seine Probleme, Tübingen, Mohr, 1922, p. 716, apud Ernst Robert Curtius, La littérature européenne et le Moyen âge latin, traduzido por Jean Bréjoux, Paris, PUF, 1956, p. 57. [NT: trecho traduzido a partir da citação em francês.]
} 
formas discursivas que fundamentam a prosa enquanto prosa, e preexistem aos modos discursivos próprios a cada tipo particular de texto. [...] Primeiramente, por sua lógica, elas estão aptas a veicular conteúdos, a "comunicar". [...] Em segundo lugar, e não menos essencial, elas tendem a se cristalizar numa arquitetura sintática que é autônoma, ou seja, separada das exigências próprias a toda comunicação (clareza, simplicidade, ordem lógica das sequências etc.). [...] Em seguida, a prosa fundamental implica na criação de conceitos e de termos que permitem sua reflexividade, ou seja, a capacidade de extrair, de generalizar, de delinear o particular à luz das categorias, de se voltar a si mesmo, de se distanciar dos conteúdos etc. [...]

Discursividade e reflexividade constituem a essência de uma prosa fundamental, a tornam apta a abraçar (quase) todos os domínios da existência humana [...]. Em qualquer língua que seja, a prosa fundamental é de natureza "universal". 9 (BERMAN, 2012, p. 44-45)

A Idade Média é também o tempo da translatio studii, um processo ao mesmo tempo topológico e linguístico que se caracteriza pela transferência dos saberes e, em particular, pela apropriação dos conhecimentos da Antiguidade, transmitidos pelos intelectuais europeus. As literaturas ocidentais são o fruto de um longo processo de assimilação, de atualização, de potencialização, de transposição do patrimônio clássico através da tradução. Ora, a literatura búlgara vai na contracorrente dessa tendência. Também é preciso destacar que, contrariamente ao mundo ocidental, o mundo eslavo não teve contato direto com o mundo clássico em razão da chegada tardia dos eslavos da Europa, depois do fim da idade clássica. Assim, o interesse pela herança clássica nos territórios búlgaros só nasceu na época do Despertar Nacional (1762$1878)^{10}$.

A identidade cultural passa forçosamente pelas trocas entre as línguas porque a língua é o elemento fundamental da cultura. E já que todo texto é traduzido de maneira diferente segundo os diversos momentos e tradições interpretativas, a temporalidade se torna a condição do modo de ser da tradução, um fato de desvelamento progressivo ou regressivo. Consequentemente, a análise tradutória não deveria limitar-se a examinar a transmissão do sentido e da forma do original, mas deveria refletir sobre as transformações históricas impulsionadas por suas traduções.

As relações da tradução e da tradição cultural estão no centro do interesse da teoria do polissistema, desenvolvida pela Escola de Tel Aviv. No artigo "The Position of Translated Literature within the Literary Polysystem" $" 11$ que estabelece os fundamentos dessa teoria, Itamar

\footnotetext{
${ }^{9}$ [NT: Trecho traduzido a partir da citação em francês.]

10 [NT: O "Despertar Nacional Búlgaro" também é chamado de "Renascimento Búlgaro".]

11 [NT: traduzido no Brasil como "A posição da literatura traduzida dentro do polissistema literário". Tradução de Leandro de Ávila Braga. Translatio, $\mathrm{n}^{\mathrm{o}} 3$, 2012, p. 3-10, Porto Alegre. Disponível em: <https://seer.ufrgs.br/translatio/article/view/34674/22321>]
} 
Even-Zohar considera a tradução como parte integrante do contexto literário, histórico e social da cultura-alvo. $\mathrm{Na}$ qualidade de um elemento entre outros elementos hierarquizados do polissistema literário, a literatura traduzida depende em grande medida das relações de força que orientam o desenvolvimento desse sistema. O conflito dos subsistemas alternativos dos quais é composto desencadeia seu dinamismo bidirecional: certos elementos se deslocam do centro em direção à periferia, outros se deslocam no sentido contrário. Ao lado dessa tensão permanente entre o centro e a periferia, a tradução realiza transferências que têm por função inscrever as obras estrangeiras no polissistema literário nacional. A interação entre essas obras e os outros elementos do polissistema determinam o lugar, central ou periférico, que sua tradução ocupa dentro dele:

\footnotetext{
Tradicionalmente, deparamo-nos com os resultados de tais transferências ou sem nos darmos conta de que tenham ocorrido ou ignorando sua origem. Já que, na prática, o ( uni- )sistema foi identificado exclusivamente com o estrato central (ou seja, cultura oficial manifestada entre outros pela língua padrão, literatura canônica, padrões de comportamento das classes dominantes), as periferias foram concebidas (quando o são) enquanto categoricamente extrassistêmicas, uma visão que coincide, evidentemente, com a "visão interna" das "pessoas-dentro-da-cultura". ${ }^{2}$ (EVENZOHAR, 1990, p. 14)
}

Uma vez incluídas no corpus dos textos que constituem uma literatura nacional, as traduções são consideradas como paradigmas. Segundo Even-Zohar existem três possibilidades para fazê-lo.

A primeira concerne “jovens” literaturas que apresentam lacunas genéricas devido à impossibilidade de redigir em pouco tempo obras em todos os gêneros. Os textos traduzidos podem preencher a falta, ou até mesmo servir de modelos aos futuros ensaios de criações literárias no âmbito de um gênero específico. Assim, Kiril Christov (1875- 1944) se inspira nas traduções dos sonetos de Shakespeare e de Petrarca para criar seus próprios sonetos; a poesia de Dimcho Debelyanov (1887-1916) é fortemente marcada pelo simbolismo; a de Atanas Daltchev (1904-1978) carrega a marca de suas traduções de Friedrich Hölderlin, Federico García Lorca, Gabriela Mistral.

A segunda possibilidade diz respeito às literaturas "fracas" ou "periféricas" que não fazem a distinção entre as obras traduzidas e as obras nacionais. A tradução permite à cultura local importar textos de valor para completar seu sistema literário. Após a queda do Muro de Berlim, a tradução dos textos modernistas, para não citar apenas James Joyce e Virginia Woolf, supriu as insuficiências do polissistema literário búlgaro.

\footnotetext{
12 [NT: Trecho traduzido a partir da citação em inglês]
} 
A terceira possibilidade pode ser observada nas literaturas "em crise", cujo sistema de valores está em meio a modificações. A literatura búlgara conheceu uma tal crise na virada do século XIX para o XX, marcada pelo grande debate entre os membros do Círculo Literário Misăl (“Pensamento”) e Ivan Vazov (1850-1921), que teve como resultado a introdução do simbolismo na Bulgária.

Apesar das afinidades mais ou menos aparentes com um desses casos apresentados, uma literatura nacional não é homogênea e monolítica, mas sim diversificada e múltipla. A relação das traduções com outros elementos de seu polissistema literário deveria então ser considerada em função de sua escolha pela cultura-alvo e da maneira como esta absorve algumas de suas normas e rejeita outras. Os textos a serem traduzidos são frequentemente selecionados segundo dois critérios, a saber, a novidade em relação à tradição cultural e à compatibilidade com suas formas já estabelecidas.

O fato de que, além de uma passagem linguística, a tradução implica uma mediação cultural suscita duas questões: a superação dos limites dos usos linguísticos habituais, a reformulação e a reforma de uma língua através da tradução são previsíveis e controláveis? Ou dependem, ao contrário, da aptidão da língua-alvo em ser submetida à força transformadora da língua-fonte?

\section{No princípio era a tradução... do Verbo}

O início da atividade tradutória na Bulgária coincide com a criação, no século IX, do alfabeto eslavo por Cirilo e Metódio. Ela é levada adiante pela missão apostólica de seus discípulos, em particular Clemente de Ocrida e Naum de Preslava (ou Naum de Ocrida), e pela obra de seus sucessores Constantino de Preslava e João, o Exarca.

Muito se especulou sobre a origem dos irmãos Constantino ${ }^{13}$ (826/827?-869) e Metódio (815?-885), ambos nascidos em Salônica. As fontes históricas estabeleceram que o pai deles era grego e a mãe provavelmente eslava. Esse último fato, nunca confirmado, alimentou uma hipótese que poderia ter explicado o excelente domínio que tinham da língua eslava, muito difundida em Salônica nessa época. A atividade literária, educativa e missionária dos dois irmãos se desenvolve num contexto político e cultural extremamente propício. É um dos períodos mais marcantes do desenvolvimento da cultura bizantina. A iconoclastia acaba de ser superada, dando lugar a um período de estabilidade política. A literatura e a arte ganharam destaque. É nessa época que começa a expansão cultural e religiosa de Bizâncio, relativa,

\footnotetext{
${ }^{13}$ Constantino adota o nome monacal de Cirilo cinquenta dias antes de morrer, quando já está gravemente doente.
} 
sobretudo, aos Eslavos dos Bálcãs e da Europa central e oriental, mas também aos habitantes da Armênia e da Geórgia, os Cazares e os Árabes.

Em 842/843, o jovem Constantino é enviado a Constantinopla para iniciar seus estudos na prestigiosa escola patriarcal junto ao palácio da Magnaura (Magna aula). Ele recebe aí o título de honra de "Filósofo", dado excepcionalmente aos homens que se distinguissem por ter uma instrução e uma erudição particulares. Nomeado bibliotecário e secretário do Patriarca da época, ele decide fazer um retiro num convento. Mas muito rapidamente requisitado pelas autoridades em Constantinopla, ele retorna para ser nomeado professor de filosofia na Escola da Magnaura.

Em vista de suas competências linguísticas (ele conhece muito bem o grego, o latim, o hebreu, o velho eslavo, em menor grau o árabe, o cazar, o persa, e provavelmente o gótico) e de sua erudição, Cirilo é enviado em missão para os Sarracenos do Califado de Bagdá (em torno de 851/856). A delegação tinha como missão resolver problemas políticos e religiosos complexos e, principalmente, aqueles a respeito dos enfrentamentos entre cristãos e muçulmanos nas zonas fronteiriças. A missão se mostra muito importante para o desenvolvimento do filósofo porque permite expandir seus conhecimentos linguísticos e aperfeiçoar suas competências retóricas. Essa possibilidade de se familiarizar com alfabetos orientais se revela muito útil ao futuro criador do alfabeto eslavo.

Em 858, o pai espiritual de Cirilo, Fócio, se torna patriarca. Dois anos mais tarde, Cirilo é enviado pelas autoridades bizantinas aos cazares, um povoado de origem turca das estepes do Baixo Volga. As questões políticas e religiosas dessa missão são afastar os cazares da influência judaica, impedir a penetração do Islã em seus territórios e convertê-los. Acompanhado de seu irmão Metódio, que ele fez com que saísse do convento, o filósofo vai à capital dos cazares para tentar convencer seu Cã a garantir a livre prática da religião cristã em seu Caganato. Suas discussões políticas e teológicas com os conselheiros judeus e muçulmanos do Cã dão os argumentos pertinentes à causa cristã num clima de rivalidade com o Judaísmo e o Islã.

Em 862, na intenção de reduzir a influência eclesiástica bávara, o príncipe da Grande Morávia, Rastilau, solicita ao imperador e ao patriarca de Bizâncio enviar-lhe um mestre capaz de "explicar [...] a verdadeira fé cristã" (D’OHRID, 1986, p. XIV) à população local em sua língua. Miguel III e Fócio decidem confiar essa missão a Cirilo. É nesse momento que o filósofo inventa o alfabeto glagolítico (glagol significa "palavra” em eslavo antigo) para poder traduzir os Livros necessários ao uso litúrgico. Muito influenciado pelos velhos alfabetos orientais, esse primeiro alfabeto eslavo, utilizado até o século XIV na Boêmia, e até o século XX na Dalmácia, é baseado nos símbolos cristãos: a cruz, o triângulo e o círculo. Mas a partir do século IX o 
glagolítico cede cada vez mais espaço para o cirílico. Entretanto, a opinião dos eslavistas quanto à paternidade do alfabeto cirílico é diversa: alguns estimam que ele tenha sido criado por um dos alunos dos dois irmãos, Clemente de Ocrida; outros sustentam que ele tenha sido introduzido por um dos seus discípulos indiretos na escola de Preslava em 893, na ocasião da coroação do imperador Simeão I e a proclamação, por parte dele, da língua eslava como língua oficial do Estado e da Igreja. O cirílico se torna progressivamente o alfabeto de todos os eslavos ortodoxos que o usam ainda hoje, a saber os búlgaros, os macedônios, os sérvios, os russos, os ucranianos e os bielorrussos.

Ligada à difusão da cultura bizantina e do cristianismo, a obra de Cirilo e Metódio é condicionada em grande medida pelo Estado bizantino, do qual eles são diplomatas e missionários. Durante os anos seguintes, eles exercem uma considerável atividade apostólica e literária. Para poder pregar aos eslavos meridionais em sua língua vernácula, eles traduzem os textos litúrgicos, principalmente os Evangelhos, os Atos dos Apóstolos e os Salmos, do grego para o eslavo antigo.

As primeiras palavras traduzidas na nova escrita glagolítica foram: "No princípio era
o Verbo, e o Verbo estava com Deus, e o Verbo era Deus". Nenhum texto poderia ser
mais apropriado do que este início do evangelho de São João para marcar a aparição
da nova escrita e a certidão de nascimento da literatura eslava. ${ }^{14}$ (DELISLE;
WOODSWORTH, 2007, p. 30$)^{15}$

Vale destacar a dificuldade objetiva de se traduzir para uma língua que ainda não está constituída como língua literária e, consequentemente, não possui os termos apropriados para transmitir conceitos religiosos, filosóficos e culturais. De fato, com suas traduções, Cirilo e Metódio estabelecem as bases da prosa fundamental eslava ao enriquecer o eslavo antigo com neologismos necessários à tradução dos conceitos. Esses empréstimos depois vão se tornar “palavras fundamentais" (BERMAN, 2012, p. 67) da língua búlgara. O domínio linguístico manifestado nos equivalentes forjados das noções abstratas demonstra suas qualidades excepcionais de exegetas, lexicólogos e tradutores. O projeto deles visa, de fato, uma "dupla apropriação: a dos 'conteúdos' das auctoritates, a das 'formas' discursivas e lexicais que as estruturam” (BERMAN, 2012, p. 54). E se a transferência do conteúdo está ligada à transmissão do Verbo, a transmissão da forma está ligada aos empréstimos lexicais. Certamente, eles fizeram cortes dos textos sagrados para poder fazer o máximo em pouco tempo. Mas essa

\footnotetext{
${ }^{14}$ [NT: Trecho traduzido a partir da citação em francês.]

15 [NT: em português: DELISLE, Jean, WOODSWORTH, Judith. Os tradutores na história. Tradução de Sérgio Bath. São Paulo: Editora Ática, 1998.]
} 
circunstância não deveria ser julgada do ponto de vista contemporâneo em termos de censura ou de adaptação. Os dois critérios pertinentes da avaliação de sua obra tradutória seriam então a coerência e a fidelidade. Essa obra segue conforme "às exigências de coerência comunicativa da translatio studii" (BERMAN, 2012, p. 71) e fiel ao espírito do texto sagrado. Assim, "nos chama a atenção a qualidade de suas traduções [de Cirilo], feitas segundo um método muito seguro, e claramente superiores a todas as outras traduções da Idade Média" (BERNARD apud DELISLE; WOODSWORTH, 2007, p. 30).

Ora, o alcance das primeiras traduções eslavas ultrapassa esses critérios estritamente tradutórios. Seu maior mérito é o de terem servido de modelos às traduções posteriores. O problema principal, mas também a audácia dos irmãos missionários, reside no uso de uma língua vernácula para fins litúrgicos. Vale lembrar ainda que durante um milênio estimou-se que o culto religioso só poderia ser praticado em uma das três línguas sagradas: o hebraico, o grego e o latim. Guiados pela convicção profunda de que "todas essas nações estão nuas sem seus próprios livros" (CONSTANTIN LE PHILOSOPHE, 1995, v. 81), Cirilo e Metódio conferem ao eslavo o estatuto de língua. Suas traduções de partes fundamentais do Antigo e do Novo Testamento, como aliás as de São Jerônimo e de Lutero, modificaram o caráter da línguaalvo, santificando-a. O objetivo da tradução da Bíblia era o de anunciar aos homens a Boa Nova numa língua que eles compreendessem, portanto, a Revelação fiel do Evangelho deveria facilitar a adesão desses homens à comunidade cristã e consolidar sua identidade religiosa e cultural. Em resumo, graças a essa tradução parcial dos textos sagrados do cristianismo, muitos séculos antes da tradução de Lutero e da King James Version, realizadas numa língua nacional, "o eslavo antigo foi promovido à posição de língua literária” (DELISLE; WOODSWORTH, 2007, p. 31). Esse ato transgressor instaurou as bases da prosa fundamental eslava e preparou o nascimento das línguas nacionais dos eslavos.

Após a morte de Cirilo, Metódio continua sua atividade tradutória. Segundo alguns, ele traduz o Patericon (D’OHRID, 1986, p. 5) (textos sobre os atos dos Pais da Igreja) e o Nomocanon (coletânea de textos de direito canônico). Segundo outros, trata-se na verdade do Typikon:

\footnotetext{
Se, portanto, Metódio planejava organizar um monastério eslavo, era lógico que traduzisse em primeiro lugar o Typikon em vez de Patericon, destinado à educação moral dos monges. Numa situação de luta ferrenha com oposição germano-latina, na falta de obras fundamentais sem as quais teria prejudicado o sistema inteiro, é difícil imaginar que Metódio se desse ao luxo de traduzir um Patericon. ${ }^{16}$ (NAUMOW, 2004, p. 27-33)
}

\footnotetext{
16 [NT: Trecho traduzido a partir da citação em italiano.]
} 
Após sua morte, o uso litúrgico da língua eslava é proibido na Morávia e os discípulos dos irmãos missionários são expulsos de seu território. Eles se refugiam então na Bulgária, junto ao rei Bóris I cujo reinado, mas principalmente o de seu filho Simeão I, é considerado como a Era de Ouro da cultura búlgara. A expressão material desse tempo de prosperidade espiritual é a criação de muitos centros literários. Fundada em 885, de acordo com a vontade de Bóris, na cidade de Plisca, a capital de seu reino, e transferida por seu sucessor Simeão para a nova capital, Preslava, a Escola de Preslava se torna rapidamente o mais importante centro cultural e literário do mundo eslavo. Os grandes eruditos da época trabalham lá, para não citar apenas os nomes de Constantino de Preslava, João, o Exarca e Chernorizetz Hrabar. Traduziram essencialmente textos bizantinos, buscando as correspondências semânticas. As traduções de Cirilo e Metódio são retomadas para reformulação sob a direção de Naum de Preslava. A atividade tradutória coabita nesse contexto com a criação poética e artística. Assim, a primeira obra literária búlgara, Nebessa (“Céus") de João, o Exarca, é de fato o prólogo da sua tradução de Uma Exposição exata da fé ortodoxa de João Damasceno. A Escola de Ocrida, por sua vez, é fundada em 886 por Clemente de Ocrida. Graças à atividade literária e cultural dessas duas escolas, a escrita eslava se difundiu a partir da Bulgária na Sérvia e na Rússia, antes de alcançar todos os povos eslavos ortodoxos.

A preservação da pureza da língua búlgara, reveladora da pureza da fé cristã, está ligada à Escola de Tarnovo - o berço da atividade artística e literária no século XIV. Essa tendência purista anda lado a lado com a afirmação do cristianismo e a afirmação do poder da aristocracia. Com a diferença do tempo da criação do alfabeto e da instauração da escrita eslava, agora traduz-se e escreve-se em búlgaro. O século XIV registra um certo "cansaço" da tradução das hagiografias e assiste ao aparecimento das primeiras traduções de obras laicas, mais frequentemente históricas. A título de exemplo poderíamos citar as crônicas bizantinas de João Zonaras, de Simeão Logóteta e Constantino Manasses, acrescentadas de glosas e de dados sobre os reis búlgaros; as narrativas da Vida de Alexandre e d'A Guerra de Tróia; a epopeia de Barlaão e Josafá ${ }^{17}$.

Não podemos falar dessa escola sem mencionar o nome do patriarca Eutímio, cujo maior mérito é o de ter iniciado uma reforma da ortografia para unificar as variantes dialetais da língua. Adepto do Hesicasmo (do grego hesychia, que significa “quietude”, "paz interior”), uma doutrina espiritual e uma prática ascética muito difundida entre os monges do Oriente cristão

\footnotetext{
${ }^{17}$ Essa adaptação cristianizada da vida de Buda foi traduzida em trinta línguas indo-europeias, o que testemunha sua grande popularidade na Idade Média. Ela teve duas traduções búlgaras: a primeira em búlgaro medieval, a segunda em búlgaro contemporâneo no século XVII.
} 
desde o século IV, o patriarca Eutímio quer purificar a língua litúrgica a fim de aproximá-la do Verbo. Partindo do pressuposto de que a pureza da mensagem implica na pureza linguística, ele realiza a correção das traduções existentes com o objetivo de atingir um nível mais elevado e mais completo da língua. O fio condutor desse trabalho de correção é a ideia de Ispravlenie knigă (a correção de livros) conforme os dogmas da Igreja ortodoxa, que já se vê ameaçada pela invasão do islã. Mantendo-se próximo à visão da tradução da Escola de Preslava, orientada para a equivalência semântica, Eutímio aspira a uma maior fidelidade formal com o original, manifestada na formação das palavras, na sintaxe, na conservação dos casos que estão desaparecendo. Em resumo, a atividade tradutória da Escola de Tarnovo marca a volta à literalidade.

Uma vez que a tradução na Idade Média tinha por função transmitir a cultura bizantina no mundo eslavo e facilitar as trocas entre as duas comunidades, traduzia-se exclusivamente do grego. Os tradutores búlgaros medievais são conscientes da grande responsabilidade de sua atividade apostólica. Imbuídos pelo desejo de atingir a perfeição, eles se impõem uma grande exigência de fidelidade ao Verbo. Além disso, como pioneiros da tradução em língua eslava, eles se beneficiam de uma liberdade ilimitada. Ao enriquecer essa língua por meio de calques e neologismos, e aperfeiçoando sua expressividade estilística, os tradutores das Escolas de Ocrida, de Preslava e de Tarnovo preparam o terreno para a literatura búlgara.

\section{A tradução, elemento constitutivo do polissistema literário búlgaro}

A era do Despertar Nacional é caracterizada por uma abertura e uma ampliação do público capaz de ler. Ela é inaugurada pela publicação em 1762 de Istorija slavjanobolgarskaja (a História eslavo-búlgara), redigida em eslavo eclesiástico pelo monge do Monte Atos, Païssii de Hilendar. A atividade tradutória que precede esse evento importante sob o plano da identidade nacional se resume à tradução do Thesaurus (1558), do pregador grego Damasceno o Estudita: uma coletânea de 36 sermões usados pelos sacerdotes. Do século XVI ao XVIII aparece uma dezena de traduções desse compêndio, conhecidas sob o nome de Damaskini. A partir do século XVII, mas sobretudo durante o século XVIII, o conteúdo delas é enriquecido por elementos edificantes. As homilias de Damasceno são doravante redigidas em língua vernácula e coabitam com hagiografias, apócrifos, narrativas religiosas, discursos moralizadores. Criteriosos no que concerne à literatura sagrada e à literatura secular, os Damaskini mobilizam esforços de muitos tradutores que os adaptam a ponto de se tornarem coautores dessas obras. 
A intensificação da atividade tradutória ao longo do Despertar Nacional visa a compensar a insuficiência de obras originais, para suprir a falta de livros, para formar o gosto dos leitores pela introdução de novos espaços e culturas. Em resumo, para abrir o caminho à criação literária original. Ao lado dos textos litúrgicos (por exemplo, a versão dita "protestante" da Bíblia realizada em 1871 por uma equipe de tradutores, dentre os quais o escritor Petko Slaveykov), traduzem-se tanto textos da Antiguidade, essencialmente do grego (Esopo, Homero, Plutarco, Sófocles, Teofrasto, Xenofonte), quanto textos contemporâneos: em primeiro lugar, do francês (Montesquieu, Voltaire, Rousseau, Lamartine, Molière, Hugo, Dumas, George Sand, etc.), do russo e do alemão. Os tradutores assumem toda a responsabilidade quanto à seleção das obras de caráter moralizador e didático, adequadas à formação do gosto do público. A tradução adquire então duas funções fundamentais: compensar as lacunas na literatura nacional e instruir os leitores.

Para dar uma ideia da atmosfera dessa época, vamos nos deter brevemente num dos primeiros projetos de tradução. Paradoxalmente, o original da primeira tradução do francês é... americano. Trata-se do ensaio The way to wealth (1758), que Benjamin Franklin publicou sob o pseudônimo de Richard Saunders, cujo título francês é La science du bonhomme Richard ou Moyen facile de payer des impôts (1778). A tradução realizada por Gavril Kristevic em 1837 apresenta as seguintes particularidades: o tradutor tinha conhecimentos insuficientes da línguafonte (ele havia feito apenas seis meses de francês), a tradução búlgara é mais próxima do original americano do que do texto francês, sua linguagem reflete o ideal da língua búlgara da época. Kristevic expõe seus princípios de tradução num prefácio no qual ele confessa ter sido conduzido pelo dever patriótico, ter buscado a clareza e a perfeição, ter utilizado a linguagem comum das mulheres, ter feito seu mestre Raïno Popovic, que não era francófono, reler seu texto. Ele confessa enfim ser contrário à bulgarização que teria deixado o texto irreconhecível: um fato excepcional para essa época em que a bulgarização incarna a reação contra a influência estrangeira (KRISTEVA, 2011, p. 377-378), época da contestação da dominação otomana, da formação da nação e da afirmação da identidade nacional.

A bulgarização se destaca então como o maior problema nessa época, que coloca em evidência a função utilitária dos textos a serem traduzidos. Ela marca a etapa transitória entre a prosa fundamental e a criação literária. Os tradutores que a praticam adaptam as obras traduzidas ao horizonte de expectativa de seus potenciais leitores. Para esse fim, eles lançam mão de muitas estratégias: a mudança dos nomes dos personagens, a transposição da ação para a Bulgária, a supressão ou o acréscimo de cenas e de referências culturais, a modificação da linguagem e do estilo dos textos-fonte. Para citar apenas um exemplo, Stefan Bobchev, o 
tradutor de Die Wasserflut am Rheine (L'Inondation du Rhin), do escritor alemão Christoph von Schmid, decide mudar o título para en Navodnenie na Dunav (L'Inondation du Danube) e bulgarizar os nomes dos personagens. Além disso, na capa, no lugar de "traduzido por", lemos “bulgarizado por Stefan Bobchev” (VON SCHMID, 1871).

Voltando à tradução de Kristevic, apesar das imperfeições, quiçá distorções que ela comporta, ela é prova de sua coragem de ir na contracorrente da tendência dominante para defender sua ideia de tradução. O paradoxo consiste na contradição entre o projeto bem claro e definido e seu resultado bem pouco convincente. Começando pelo título, Mudrost dobrago Riharda (La Sagesse du bonhomme Richard), que é a prova de uma dupla deformação em relação ao título original e ao título francês.

Nessa época as seguintes questões essenciais são feitas pela primeira vez: $O$ que precisa ser traduzido? Por quem? Como? A primeira concerne à escolha dos textos em função de sua tipologia e assunto, e dos tradutores em função de seus conhecimentos linguísticos e competências culturais. A segunda toca o problema da técnica de tradução: adaptação ou valorização do original. Essas questões desencadearam a versão búlgara da querela eterna entre Antigos e Modernos, ou seja, dos velhos contra os jovens. O campo dos velhos reúne Necho Bontchev, Marin Drinov, Vassil Droumev - adeptos da imitação dos grandes autores clássicos em vista da formação do gosto literário. Os jovens, dos quais fazem parte Raïko Jinzifov, Lyuben Karavelov, Christo Botev, não consideram a difusão da literatura estrangeira clássica como indispensável à formação do gosto dos leitores búlgaros e, ao invés disso, encorajam a de obras contemporâneas que respondem a suas necessidades particulares.

Com a independência, em 1878, vem o reconhecimento do ofício do tradutor. Já que as grandes obras da literatura ocidental não estavam acessíveis aos leitores que não falam as línguas europeias, cabe aos tradutores compensar esse atraso. Vale ressaltar que os tradutores da época são ao mesmo tempo escritores conscientes da importância da tradução para a inserção da literatura nacional na literatura mundial, e para a satisfação das aspirações específicas do público. Esse contexto cultural particular condiciona a seleção de textos segundo uma certa escala de valores, em vista da distância temporal entre os momentos de sua criação e de sua tradução, e uma finalidade privilegiada. A seleção é feita em função de duas abordagens diferentes em relação ao lugar da literatura na vida de uma pequena nação. A primeira abordagem, defendida por Pencho Slaveykov, considera a constituição da literatura búlgara como o resultado de influências estrangeiras. A segunda, adotada por Ivan Vazov, estima que a literatura nacional deve se fechar nela mesma ou se voltar para o passado. 
Ao longo desses trinta últimos anos do século XIX, observa-se uma assimilação condensada das obras clássicas a fim de compensar o atraso em relação aos países europeus. As primeiras christomatii, das antologias de trechos de textos considerados como os melhores espécimes da literatura mundial, são editadas. No que concerne à literatura francesa, poderíamos mencionar as traduções dos trechos de Hernani de Victor Hugo por Ivan Vazov, que se inspira nele para escrever pastiches. Pelo ímpeto patético, a ênfase e as ideias românticas, o romance Pod igoto (Sob o jugo) desse escritor lembra Les mystères de Paris de Eugène Sue e Les Misérables de Hugo. As revistas literárias publicam muitas traduções, para não citar apenas Biblioteka Sveti Kliment (Bibliothèque Saint Clément/Biblioteca São Clemente), dirigida por Petko Karavelov, na qual, de 1888 a 1891, sai um grande número de traduções de Mara Beltcheva (Assim falou Zaratustra, de Nietzsche), Ekaterina Karavelova (Une nuit, de Maupassant, Hérodias, de Flaubert), Aleko Konstantinov (Tartuffe, de Molière). Quanto às línguas das quais de traduz mais, o francês segue o russo, e precede o alemão e o inglês. Observemos, entretanto, que no final do século XIX traduzem-se também muitas obras medíocres. Esse fenômeno é explicado pela atividade tradutória acelerada que não é sempre capaz de avaliar corretamente a literariedade dos textos-fonte.

A atividade cultural na Belle Époque é assinada pelo círculo formado em volta da revista "Misăl" ("Pensamento") (1892-1907), a revista mais significativa na virada do século XX. Dentre os membros do círculo, presidido pelo doutor Kristev, redator chefe da revista, encontramos grandes poetas e escritores da época: Peyo Yavorov, Pencho Slaveykov, Petko Todorov, Kiril Christov. A maior preocupação de seu redator chefe era a de desenvolver o gosto estético do leitor e, portanto, a revista publica na rubrica Traduções textos estritamente traduzidos do original. Trata-se tanto de obras antigas quanto de contemporâneas russas, francesas, alemãs, inglesas. Os membros do círculo Misăl (Pensamento) arriscam as primeiras críticas sobre a tradução. Assim, deve-se a Pencho Slaveykov não somente em torno de cinquenta textos traduzidos do alemão, do francês e do russo, mas igualmente as primeiras reflexões modernistas sobre a tradução. Em resumo, a novidade consiste numa tentativa de conciliar a pesquisa estética com a qualidade tradutória.

Ao longo da primeira metade do século XX, já é possível observar uma sincronização do processo literário búlgaro com o da literatura mundial, consequência da curiosidade de conhecer obras literárias publicadas no exterior. E se não podemos afirmar de uma maneira categórica que o atraso está completamente compensado, podemos notar o esforço de traduzir quase que simultaneamente obras contemporâneas: por exemplo, Konstantin Konstantinov traduz Terre des hommes, de Antoine de Saint-Exupéry, em 1943, um ano após a publicação 
do livro. Durante o entreguerras, muitas revistas literárias se dão conta da evolução literária no mundo e lançam reflexões de vanguarda. O equilíbrio entre a literatura búlgara e a literatura mundial é mais ou menos atingido. A extensão da tradução conduz à instauração de uma verdadeira indústria tradutora. Esta última leva infelizmente uma forte marca comercial que relega a literariedade, frequentemente substituída pelo divertimento.

Se a palavra-chave da atividade tradutória na Bulgária da Segunda Guerra mundial nos anos 90 do século XX é o hermetismo, a palavra que qualifica seu estado atual seria a abertura. A pressão exercida pelo contexto político sobre a produção artística e literária do pós-guerra afeta, entre outras coisas, a escolha dos textos a serem traduzidos e a censura de todo elemento suspeito. É a era da tradução em massa de obras soviéticas que exaltam o comunismo e fazem a propaganda da supremacia do poder dos soviéticos. Sabendo que se traduz muito pouco das outras línguas (à exceção do russo e de algumas obras clássicas) para o búlgaro, os esforços dos tradutores estão concentrados na tradução do búlgaro para as línguas majoritárias. Podemos mencionar a título de exemplo Sous le joug (Sob o jugo), de Vazov, que teve quatro traduções em francês $(1899,1957,1976,2007)$, das quais duas realizadas neste período. A colaboração entre o tradutor e o supervisor até os anos 1990 resulta a maioria dos casos em traduções adequadas do ponto de vista da expressão linguística, entretanto, pouco respeitosas em relação ao original e, portanto, inadequadas. A grande extensão da tradução a partir dos anos 1990 é acompanhada de um movimento crítico. Os próprios tradutores adquirem o direito e a coragem de se pronunciarem sobre seu próprio trabalho assim como sobre o trabalho de seus colegas. Muito controlada nos anos 1970-1990, sua reflexão se liberta da pressão ideológica na virada dos séculos XX e XXI.

A evolução histórica da tradução na Bulgária dá lugar a algumas conclusões. A tradução dos Livros litúrgicos por Cirilo e Metódio contribui para a instituição do eslavo como língua literária, afirmando sua dignidade linguística. Com o nascimento da língua nacional, a tradução se inscreve num vasto projeto ideológico e religioso que prepara o terreno para a literatura búlgara. A intensificação da atividade tradutória ao longo do Despertar Nacional visa a compensar a insuficiência das obras originais, formar o gosto do leitor, dar modelos à criação literária. A partir da Independência, as traduções respondem cada vez mais às exigências da cultura búlgara para poderem se inserir em seu polissistema literário. Sujeita a uma forte pressão ideológica no período do pós-guerra, a tradução finalmente se emancipou de toda censura política hoje.

A tradução demanda, incontestavelmente, um trabalho linguístico com o objetivo de explicitar o sentido do texto. Para esta finalidade, ela não deve simplesmente visar a se adaptar 
à língua estrangeira. Culturalmente carregada, ela é orientada a um público que quer ler e aprender alguma coisa sobre um modo de vida estrangeiro sem com isso desejar viver a vida das tribos da Nigéria ou dos guetos "roms" dos Bálcãs. A civilização ocidental está habituada à expansão de seus modelos sem estar particularmente inclinada a aceitar os modelos do Terceiro Mundo. O tradutor, num tal contexto, tende fácil e inconscientemente a simplificar o texto redigido numa língua "fraca" para adaptá-lo ao paradigma imposto por sua própria língua "forte". O francês foi, historicamente falando, o modelo emblemático disso. O búlgaro, ao contrário, soube aproveitar a tradução para reforçar sua prosa fundamental.

\section{Referências}

BENJAMIN, Walter. La tâche du traducteur. In : . Euvres. Tradução de Maurice de Gandillac. Paris : Gallimard, 2000, p. 244-262.

BERMAN, Antoine. Jacques Amyot, traducteur français. Essai sur les origines de la traduction en France. Paris : Belin, 2012.

L'épreuve de l'étranger. Culture et traduction dans l'Allemagne romantique. Paris : Gallimard, 1984.

_. Tradition - Translation - Traduction. Po\&sie, $\mathrm{n}^{\mathbf{0}}$ 47, 1988, p. 85-98.

CLEMENT D'Ohrid. Prostanno žitie na arhiepiscop Metodi [Hagiographie de l'archevêque Méthode]. Stara bălgarska literatura. Sofija : Bălgarski pisatel, 1986, iv.

. Prostanno žitie na Konstantin-Kiril [Hagiographie de Constantin-Cyrille]. Stara bălgarska literatura, Sofija : Bălgarski pisatel, 1986, iv.

CONSTANTIN LE PHILOSOPHE. Proglas kăm Evangelieto [Prólogo ao Evangelho segundo São João]. Sofija: Agata-A, 1995.

CURTIUS, Ernst Robert. La littérature européenne et le Moyen âge latin. Tradução de Jean Bréjoux. Paris : PUF, 1956.

DELISLE, Jean ; WOODSWORTH, Judith. Les traducteurs dans l'histoire. Ottawa : Presses Université Ottawa, 2007.

DESCARTES, René. Discours de la méthode. Paris: Flammarion, 1966.

EVEN-ZOHAR, Itamar. Polysystem Theory. Poetics Today, v. 11, nº 1, p. 9-26, 1990.

The Position of Translated Literature within the Literary Polysystem. Poetics Today, v. $11, n^{\circ} .1$, p. $46-51,1990$.

KRISTEVA, Irena. Déformations inconscientes en traduction. In : Dire, Écrire, Agir en Français. Kragujevac: Nasledje, 2011. 
NAUMOW, Aleksander. Idea-immagine-testo. Studi sulla letteratura slavo-ecclesiastica, a cura di Krassimir Stantchev. Edizioni dell'Orso, 2004.

STEINER, George. Après Babel. Une poétique du dire et de la traduction. Tradução de Lucienne Lotringer. Paris : Albin Michel, 1978.

TROELTSCH, Erns. Der Historismus und seine Probleme. Tübingen: Mohr, 1922.

VON SCHMID, Christoph. Navodnenie na Dunav. Tradução de Stefan Bobchev. Carigrad: Promišlenie: 1871.

Recebido em: 15/12/2018

Aceito para publicação em: 09/04/2019 